\title{
A comparison of the Ponzo illusion with a textural analogue
}

\author{
MARK B. FINEMAN and JEFFREY CARLSON* \\ Southern Connecticut State College, New Haven, Connecticut 06515
}

\begin{abstract}
The inappropriate constancy scaling notion of geometric illusions was explored by employing a textural analogue of the Ponzo figure. Ten Ss estimated the length of a horizontal line by equating it with varying companion lines in the context of the Ponzo figure, a textural analogue, and a baseline control in which the lines appeared with no surrounding contours. The textural analogue had the added feature of imposing no contours at the ends of the horizontal lines. It was found that length estimates were significantly different between the horizontals of the Ponzo figure and control stimuli, but not between the texture figure and a context-free control. The results suggest that inappropriate constancy scaling plays a minor role at best in the perception of geometric illusions.
\end{abstract}

One category of theory that attempts to explain the operation of geometric illusions assumes that the failure to equate physically identical elements in two-dimensional displays may be attributed to inappropriate constancy scaling (Day, 1972; Gergory, 1963; Tausch, 1954). Such a theory explains the Ponzo illusion by proposing that the angular portion of the figure suggests depth in the manner of linear perspective, and so the more "distant" of the two lines is perceived as larger when both lines subtend equal visual angles.

Other theories, the assimilation theory in particular, discount the importance of constancy scaling and emphasize the presence of contours at the end points of the lines to be equated (Fisher, 1968, 1969; Pressey, 1971).

Demonstrations and experiments that support the misplaced scaling notion have not always been careful to isolate depth features of a display while controlling for the occurrence of end contours. For example, Leibowitz, Brislin, Perlmutter, and Hennessy (1969) presented evidence that the size of two lines of equal retinal extent were misjudged when superimposed on a photograph of an open field, a scene which supposedly portrayed strong textural cues. It is contended that their context may not have eliminated the occurrence of end contours, particularly because texture was more densely concentrated around the upper horizontal line than around the lower line. In fact, a close examination of the figure suggests that linear perspective cues may have been present as well. The general problem is that linear perspective cues generally produce end contours at the same time.

In the present experiment, an attempt was made to evaluate size estimations of physically identical horizontal lines when embedded in a depth context created by texture alone. The stimulus was arranged in such a way that end contours were not present and so

\footnotetext{
*Requests for reprints may be sent to: Mark B. Fineman, Southern Connecticut State College, Department of Psychology, 501 Crescent Street, New Haven, Connecticut 06515.
}

afforded an opportunity to assess the role of constancy scaling alone. It was felt that this procedure would help to isolate individual factors contributing to the Ponzo illusion and would more clearly delineate the relative importance of these factors in the perception of the figure.

\section{METHOD \\ Subjects}

The Ss were 10 undergraduate students (four males and six females) at Southern Connecticut State College. All were unpaid volunteers naive as to the purposes of the experiment.

\section{Apparatus}

The stimuli consisted of three series of black-and-white transparencies, one series for each condition, with 11 transparencies per series. The stimuli were rear-projected by means of a Kodak Carousel projector (Model 850) equipped with a 4- to 6-in. Ektanar zoom lens. Each projected stimulus measured $33.60 \times 50.20 \mathrm{~cm}$.

A pair of black, parallel, horizontal bars occurred in every stimulus, and in every case the upper bar measured $40 \mathrm{~mm}$ in length and $3 \mathrm{~mm}$ in width, and was separated from the lower bar by $16.20 \mathrm{~cm}$. Within each series, the lower bar was varied in size from 32 to $52 \mathrm{~mm}$ in $2-\mathrm{mm}$ steps, with the width of bars equal to that of the upper bar. In the first series (control stimuli), the bars were presented against a uniform white background, while in the second series, they were presented within the context of an angular figure measuring $47 \mathrm{~cm}$ to a side, forming an angle of $36 \mathrm{deg}$ (the traditional Ponzo figure). In the third series, the bars were superimposed on a dot pattern modified from one originally published by Gibson (1950). This pattern, the textural analogue of the Ponzo figure, gave the appearance of a planar surface with the upper portion systematically receding from the lower portion (see Fig. 1). The bars were positioned in such a manner that they occurred only between rows of dots and were never superimposed directly on rows.

The S's head was held stationary in a head- and chinrest so that the chin was located $2.25 \mathrm{~m}$ from the surface of the screen. A remote control switch located near the S's hand permitted him to advance the slide magazine in either a forvard or backward direction.

\section{Procedure}

Individual Ss were seated and made comfortable in the 


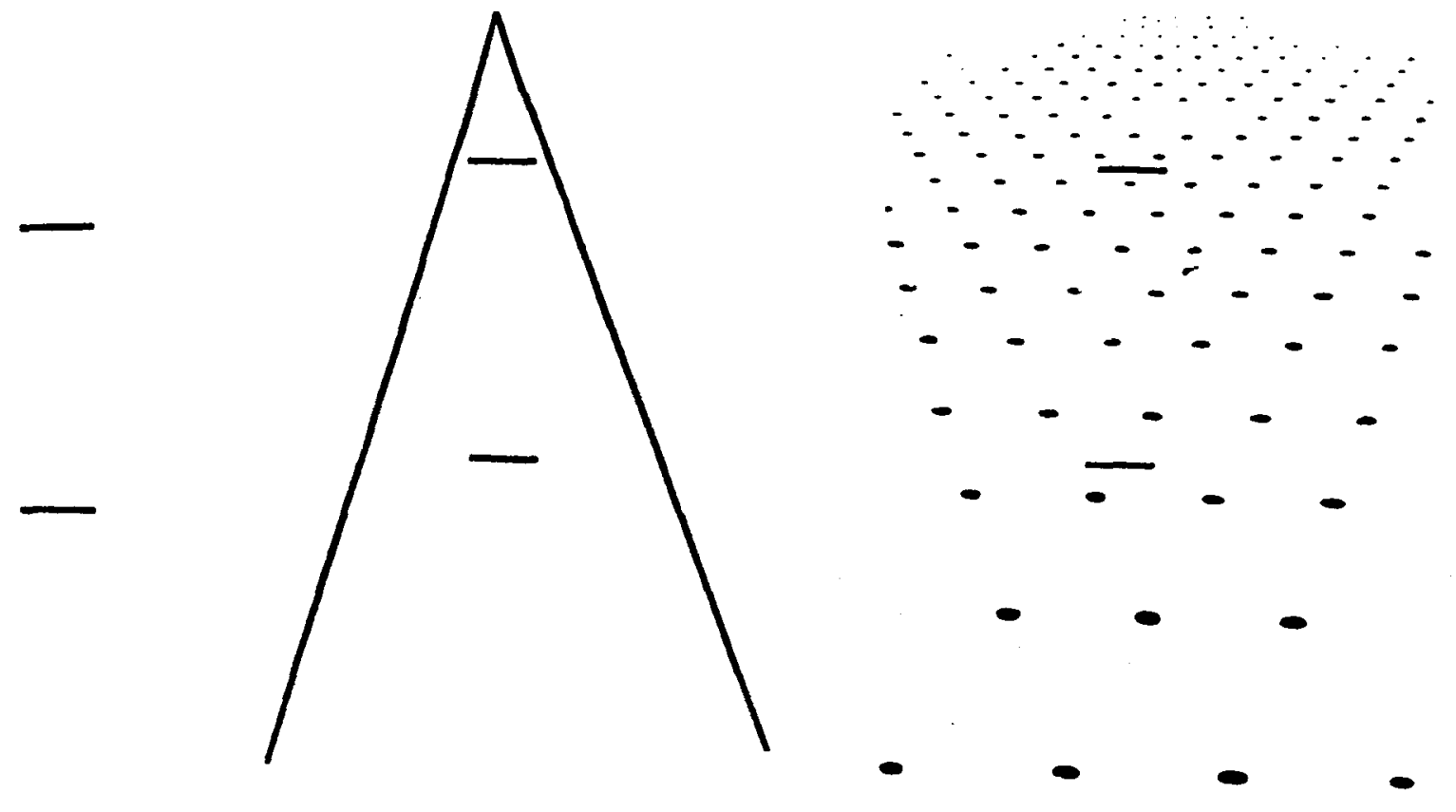

Fig. 1. A control stimulus (A), the Ponzo figure (B), and the textural analogue (C). All of the horizontal lines are of equal length.

headrest. If Ss normally wore corrective lenses, they were told to do so for the duration of the experiment. Then the advance switch for the projector was placed in S's hand and he was instructed in its use.

All Ss were told that they would view several series of slides and that in each case two horizontal bars would be visible; their task would be to continue advancing the slides until the lower line appeared to be the same length as the upper line. The transparencies were presented in order within a given series, and each series of stimuli was presented four times, twice in an ascending order and twice in a descending order, for a total of 12 trials. The 12 trials were presented in a different random order for each $S$. Before a given trial commenced, the $E$ located the proper stimulus series, positioned that portion of the magazine above the projector carrier, and told the $S$ to press the advance button (for ascending trials) or the reverse button (for descending trials).

\section{RESULTS}

The Ss tended to overestimate all of the upper lines, although mean estimates of the upper lines most closely approached the physical size of the line in the control condition $(\bar{X}=41.75 \mathrm{~mm}, \mathrm{SD}=0.90)$. The mean of length judgments for the upper line in the Ponzo figure was $46.40 \mathrm{~mm}(\mathrm{SD}=1.66)$, while the mean of estimates of the line embedded in the texture was $43.00 \mathrm{~mm}$ (SD $=1.36$ ). An analysis of variance indicated a significant difference between conditions, $F(2,27)=21.40$, $p<.01$. One-tailed tests for the differences between individual means showed that judgments of the Ponzo upper line were significantly larger than those of the context-free control $(t=5.05, p<.005)$, and those of the textural analogue $(t=4.89, p<.005)$. Judgments of the textural analogue line were not significantly larger than those of the line in the control condition $(t=1.40)$.

\section{DISCUSSION}

These results indicate quite clearly that the inappropriate constancy scaling hypothesis alone is not sufficient to explain the nature of the Ponzo illusion. In the textural analogue figure, for example, judgments of the length of the upper line were not significantly larger than those of the control stimulus. In addition, judgments of the upper line in the Ponzo figure were found to be significantly larger than those of the textural analogue. The latter finding might best be considered cautiously, because no attempt was made to equate the potential depth conveyed by the lines in the Ponzo form with that conveyed by texture.

When end contours were presented in conjunction with the horizontal lines, as in the Ponzo figure, estimations of line length were consistently misjudged in relation to the physical size of the lines, as indicated by the highly significant difference between size estimations for the Ponzo figure and the control stimulus.

The results strongly suggest that constancy scaling is of minor importance in the Ponzo illusion and that evidence which had supported that hypothesis may have erred by not truly isolating individual depth cues. On the other hand, an alternate hypothesis does not readily suggest itself. The fact that the presence of contours at the ends of the horizontals in the Ponzo illusion is of utmost importance supports an assimilation theory, although other notions, such as lateral inhibition, may also suffice. The authors hope to explore these alternate 
hypotheses using techniques similar to those described in this paper.

\section{REFERENCES}

Day, R. H. Visual spatial illusions: A general explanation. Science, 1972, 175, 1335-1340.

Fisher, G. H. An experimental and theoretical appraisal of the inappropriate size-depth theories of illusions. British Journal of Psychology, 1968, 59, 373-383.

Fisher, G. H. Towards a new explanation for the geometrical illusions; I. The properties of contours which induce illusory distortion. British Journal of Psychology, 1969, 60, 179-185.

Gibson, J. J. Perception of the visual world. Boston: Houghton-Mifflin, 1950.
Gregory, R. L. Distortion of visual space as inappropriate constancy scaling. Nature, 1963, 199, 678-680.

Leibowitz, H., Brisiin, R., Perlmutter, L., \& Hennessy, R. Ponzo perspective illusion as a manifestation of space perception. Science, $1969,166.1174-1176$.

Pressey, A. W. An extension of assimilation theory to illusions of size, area, and directuon. Perception \& Psychophysics, 1971, 9. 172-176.

Tausch, R. Optische Taeuschungen als artifizielle Effekte der Gestaltungsprozesse von Groessen- und Formenkonstanz in der natuerlichen Raumwahrnehmung. Psychologische Forschung, 1954, 24, 299-348.

(Received for publication December 12, 1972; revision received February 21,1973 .) 